\title{
A AMAZÔNIA BRASILEIRA COMO RECURSO DE PODER NO SISTEMA INTERNACIONAL ${ }^{1}$
}

\author{
THE BRAZILIAN AMAZON AS A RESOURCE OF POWER IN THE \\ INTERNATIONAL SYSTEM
}

DOI: $10.5380 / \operatorname{cg} \cdot v 10 i 2.79042$

Amanda Kristtine Schulz 2

Charles Alexandre Souza Armada 3

\begin{abstract}
Resumo
A presente pesquisa tem como objetivo entender a forma que o Brasil utiliza seus recursos naturais, principalmente a Amazônia, enquanto instrumento de barganha no Sistema Internacional. A partir do aumento da consciência acerca da importância do meio ambiente, do seu entendimento como um direito fundamental e da crise ambiental global da atualidade, passa a existir uma maior preocupação da relação do homem com a natureza e a temática ultrapassa as questões nacionais. O Brasil, nesse cenário, desempenha papel fundamental, uma vez que contém reservas de recursos naturais de grande relevância para todo o planeta e que a degradação de sua biodiversidade é capaz de impactar todas as nações. Nesse sentido, o país é uma potência ambiental e detentor de poder no cenário internacional, contudo está permitindo que esse instrumento de barganha seja utilizado de maneira coercitiva contra si. A fim de atingir seus objetivos, este trabalho empregou o método indutivo de pesquisa através de um embasamento teórico fundamentado em pesquisas bibliográficas e documentais, baseados principalmente em conceitos das Relações Internacionais de poder e focados em identificar o potencial da natureza brasileira como recurso de poder e de como o país utiliza a sua natureza dessa forma.
\end{abstract}

Palavras-Chave: Crise Ambiental Global; Direitos Humanos; Recurso de Poder; Segurança Internacional.

\begin{abstract}
This research aims to understand how Brazil applies its natural resources, mainly the Amazon, as a bargaining tool within the International System. Due to the increasing awareness about the importance of the environment, its understanding as a fundamental right and the current global environmental crisis, there is a greater concern for the relationship between man and nature and the theme goes beyond national issues. In this scenario, Brazil plays a fundamental role, at first by containing natural resource reserves of great relevance to the International System and foremost because the degradation of its biodiversity would have the capacity to impact the entire planet. In this sense, Brazil is an environmental power and holds power in the International System, however, it is allowing this bargaining instrument to be used in a coercive manner against itself. In order to achieve its objectives, this article employed the inductive method of research through a theoretical basis based on bibliographical and documentary research, based mainly on concepts of power in International Relations and focusing on identifying the Brazilian nature potential as a resource of power and how the country uses its nature in this way.
\end{abstract}

Keywords: Global Environmental Crisis; Human Rights; Power Resource; International Security.

\footnotetext{
${ }^{1}$ Este artigo está licenciado sob a Licença Creative Commons Attribution (CC BY 4.0), sendo permitido o compartilhamento com reconhecimento da autoria e publicação inicial nesta revista.

${ }^{2}$ Graduada em Relações Internacionais da Universidade do Vale do Itajaí - UNIVALI - campus Itajaí. Email: amanda.ks98@gmail.com. ORCID: https://orcid.org/0000-0002-9457-4106.

3 Doutor em Ciência Jurídica pela Universidade do Vale do Itajaí - UNIVALI, e em Derecho Ambiental y de la Sostenibilidad pela Universidade de Alicante, na Espanha. E-mail: charlesarmada@hotmail.com. ORCID: https://orcid.org/0000-0003-2921-6182.
} 


\section{INTRODUÇÃO}

A dinâmica da economia mundial a partir da segunda metade do século XX foi baseada num desenvolvimento econômico que desconsidera a finitude dos recursos naturais e as limitações impostas pelo meio ambiente. Assim, uma preocupação acerca da relação do homem com a natureza, da exploração dos recursos naturais, bem como polêmicas, visões e debates acerca de iminentes catástrofes ecológicas, que colocariam em risco a vida do homem no planeta, começam a ter uma maior prioridade e visibilidade.

A crise ambiental global da atualidade tem sua fonte no desequilíbrio dos ecossistemas marinhos, na poluição dos mares, no desflorestamento, na diminuição da biodiversidade da fauna e flora, no aumento da temperatura global, nas mudanças climáticas, entre outros. As agressões ao meio ambiente e os problemas decorrentes da sua proteção atingiram escalas internacionais, gerando danos ao ecossistema global. Devido à sua característica transfronteiriça, a crise ambiental global da atualidade e seus riscos ultrapassam as questões nacionais, bem como temas multidisciplinares inerentes aos campos sociológico, antropológico e dos Direitos Humanos.

O Brasil desempenha papel fundamental num contexto contemporâneo sócio-políticoeconômico de crise ambiental global. O país tem em seu território de 15 a 20\% da biodiversidade do planeta e detém 60\% da floresta amazônica, a qual é um importante reservatório de carbono, um regulador crítico da temperatura e uma fonte importante de água doce. (PESSOA E SANTOS, 2014). O país concentra recursos naturais de grande relevância para o Sistema Internacional e a destruição ou degradação da sua biodiversidade impactaria muitos Estados, senão todo o planeta. Somado a isso, do ponto de vista legal, o Brasil é signatário de quase todos os acordos ambientais multilaterais, possui um direito penal ambiental e consagra em seu texto constitucional o meio ambiente como um direito fundamental.

Nesse sentido, a partir do entendimento da atual crise ambiental global e da importância dos recursos naturais brasileiros nesse contexto, serão utilizados conceitos das Relações Internacionais de Morgenthau, Nye e Klare para procurar entender de que maneira o Brasil utiliza, ou não, a sua biodiversidade e seus recursos naturais como instrumento de recurso de poder no Sistema Internacional, tendo como enfoque a Amazônia Brasileira. Busca-se fazer isso através de um retrato da crise ambiental global da atualidade, da conceituação de "Recurso de Poder", da identificação do potencial da natureza brasileira como instrumento de recurso de poder e de como o país utiliza a sua natureza dessa forma.

Vale esclarecer que a opção analítica adotada se baseia em autores norte-americanos, economistas do chamado neo-malthusianismo, com recorte geográfico europeu e/ou anglófono. Assim, utilizou-se de um embasamento teórico fundamentado em pesquisas bibliográficas e documentais e critérios qualitativos, a fim de atingir os objetivos que a pesquisa apresenta. A bibliografia utilizada é, em grande parte, no idioma português, embora referências em inglês 
também tenham sido consideradas. Após o levantamento das fontes bibliográficas, deu-se continuidade à execução da pesquisa através da contextualização teórica da literatura selecionada.

\section{A CRISE AMBIENTAL GLOBAL DA ATUALIDADE: O MEIO AMBIENTE GLOBAL SOB NOVOS ENFOQUES}

A problemática da degradação ambiental não era uma prioridade da sociedade até poucos anos atrás. O mundo pós Segunda Guerra Mundial estava focado na manutenção da paz e da segurança internacional, baseado na industrialização e modernização como única maneira de estimular o crescimento econômico. (NIENCHESKI, 2014). Esses meios de desenvolvimento baseados na produção, no consumo e no descarte desenfreado, não consideravam a finitude dos recursos naturais e as limitações impostas pelo meio ambiente. (ARMADA, 2017). As agressões ao meio ambiente e os problemas decorrentes da sua proteção atingiram escalas internacionais, gerando danos ao ecossistema global, como a mudança do clima, a degradação dos oceanos, a destruição da camada de ozônio, a crise da biodiversidade e dos recursos hídricos. (ARMADA, 2016).

Tendo em vista que os hábitos de consumo da humanidade geram uma demanda maior que a capacidade da Terra de regenerar os recursos naturais, a relação entre o meio ambiente e um crescimento econômico ilimitado é incompatível, levando o planeta a uma situação limite, que coloca em risco a permanência do homem na Terra. (WWF, 2016). Steffen et al. (2015) introduziram os Limites Planetários, ou seja, os limites ambientais seguros dentro dos quais a humanidade pode se desenvolver e operar de forma segura, sem que os impactos causados ao meio ambiente sejam irreversíveis e inviabilizem a vida humana. Os processos envolvidos nos Limites Planetários são: mudanças climáticas, perda da biodiversidade, degradação da camada de ozônio, acidificação dos oceanos, ciclos biogeoquímicos, abusos no uso do solo, mudanças no uso da água, emissão de aerossóis para a atmosfera e poluição química. Segundo estudo publicado em 2015, quatro desses limites já foram ultrapassados: a perda da biodiversidade, as mudanças climáticas, as alterações do ciclo do nitrogênio e os abusos no uso do solo.

As atividades antrópicas têm alterado também a manutenção da temperatura da Terra, agravando o fenômeno das mudanças climáticas, intensificado principalmente pelo aumento do desmatamento, das queimadas para agricultura e criação de gado, assim como por processos industriais de geração de energia com uso de combustíveis fósseis. A concentração de gases que produzem o efeito estufa na atmosfera atingiu seus níveis mais elevados em 800 mil anos. (VIEIRA, 2015). Segundo o Acordo de Paris (2015), firmado em 2015 por 195 países, tem-se um consenso de que o aumento da temperatura global não deve ultrapassar $2{ }^{\circ} \mathrm{C}$, pois tal aumento causaria danos como secas, inundações, desertificação, calor intenso, temperaturas excessivas, falta d'água, redução 
da produção agrícola, aumento no preço dos alimentos, desastres naturais, refugiados ambientais, entre outros.

Devido à sua característica transfronteiriça, a crise ambiental global da atualidade e seus riscos ultrapassam as questões nacionais e atingem temas multidisciplinares inerentes aos campos sociológico, antropológico e dos Direitos Humanos. Assim, a temática ambiental foi trazida para o centro do debate político, forçando os Estados a discutirem coletivamente sobre o assunto. (NIENCHESKI, 2014)

O aumento da consciência ecológica levou à percepção de que a proteção e manutenção do meio ambiente estão intrinsecamente relacionados a um padrão de vida humano digno, uma vez que não há como defender o direito à vida sem proteger o meio em que ela se desenvolve. (NIENCHESKI, 2014). Bosselmann (2010, p. 91) assegura que os:

[...] direitos humanos e o meio ambiente estão inseparavelmente interligados. Sem os direitos humanos, a proteção ambiental não poderia ter um cumprimento eficaz. Da mesma forma, sem a inclusão do meio ambiente, os direitos humanos correriam o perigo de perder sua função central, qual seja, a proteção da vida humana, de seu bem-estar e de sua integridade.

A proteção dos Direitos Humanos passa a ser atrelada, portanto, à proteção do meio ambiente, porque defender significa não somente conservar os recursos naturais para as futuras gerações, mas também proporcionar melhores condições de vida para a população. Ou seja, o meio ambiente passa a ser entendido como um direito fundamental, uma vez que auxilia na proteção da dignidade da pessoa humana. (COLOMBO, 2007).

$\mathrm{O}$ entendimento do meio ambiente como um direito humano incorporou nas agendas nacionais e internacionais o princípio de solidariedade, provocando uma inter-relação entre Estado e cidadão e entre os diversos Estados, já que o direito ao meio ambiente interessa ao Homem como um todo, sem fronteiras, exigindo ações conjuntas e solidárias para sua efetivação. (CALSSING, 2010).

A limitação dos Estados nacionais no combate à crise ambiental global da atualidade é evidente, sendo incapazes ou impossibilitados de lidar com os novos desafios impostos, agravados pela falta de uniformidade de ações e interesses. (ARMADA, 2016). Conforme exposto nesta seção, não somente a questão climática, mas todas as questões ambientais aparecem como chave das relações internacionais no século XXI, pois são de interesse de todos os seres humanos, de tal forma que 159 países já possuem o meio ambiente como direito social garantido constitucionalmente, segundo o Comparative Constitution Project (2020), ou seja, o reconhecem como essencial para a sobrevivência e qualidade de vida de seus cidadãos. Assim, a maneira como a comunidade internacional se relaciona com o meio ambiente afetará o futuro da humanidade. (PEREIRA, 2015). 


\section{O RECURSO DE PODER DA DIVERSIDADE BRASILEIRA: A IMPORTÂNCIA DOS RECURSOS NATURAIS E MATERIAIS BRASILEIROS}

A temática ambiental é uma questão-chave nas relações internacionais do século XXI. O fracasso da sociedade internacional de gerenciar as situações ambientais no longo prazo, assim como sua incapacidade de lidar com a crise ambiental global da atualidade, afetam a dinâmica do Sistema Internacional, uma vez que provocam mudanças nas relações de poder entre os Estados.

A política internacional consiste, necessariamente, em política do poder. Desde as guerras de Napoleão, tinha-se que a luta pelo poder no cenário internacional era um fenômeno temporário, que tendia a desaparecer uma vez que as condições históricas que lhe deram origem fossem eliminadas. Contudo, a luta pelo poder é universal, no tempo e no espaço. Com o passar dos séculos, independentemente de condições sociais, econômicas e políticas, muitos Estados se confrontam entre si em disputas pelo poder. (MORGENTHAU, 2003).

Morgenthau (2003) entende o poder político como o meio de alcançar os objetivos da nação. Sejam quais forem os fins da política internacional, liberdade, segurança, prosperidade ou poder em si mesmo, eles consistem em uma luta pelo poder. O poder permite àqueles que o detém ter controle sobre as ações daqueles que não o possuem. "Ele [o poder] pode ser exercitado por meio de ordens, ameaças, pela autoridade ou carisma de um homem ou de um órgão, bem como pela combinação de quaisquer desses meios". (MORGENTHAU, 2003).

A base de toda política nacional e internacional, segundo Morgenthau (2003, p. 55)

[...] é formada pela interação da expectativa de benefícios, do medo de desvantagens e do respeito ou amor por homens e instituições... Sempre houve uma tendência a reduzir o poder político à aplicação efetiva do poder, ou pelo menos a identificá-lo com ameaças bem sucedidas de força e persuasão, com o menosprezo do carisma.

Nesse sentido, tem-se ainda quatro distinções: poder e influência; poder e amor; poder utilizável e não utilizável; poder legítimo e ilegítimo. Poder se distingue de influência no sentido de que persuadir é diferente de coagir ou impor uma vontade. Poder se diferencia da força quando se tem a abdicação do poder político em favor do poder militar. O que difere o poder utilizável do não utilizável é o fato de se possuir um recurso interno e utilizá-lo como instrumento de política exterior ao seu favor, com o objetivo de influenciar os pensamentos e ações do outro. Por fim, poder legítimo é aquele cujo exercício é justificado moral e legalmente, enquanto poder ilegítimo não tem qualquer fundamento para sua execução. (MORGENTHAU, 2003).

Para Nye (2016), poder também é entendido como a capacidade de alterar o comportamento de outra parte para atingir um objetivo, podendo exercê-lo através de três formas: coerção, pagamentos e/ou atração, este último também conhecido como soft power. A habilidade de controlar o outro, portanto, está geralmente atrelada ao fato de se possuir certos recursos, os quais 
podem ser população, território, recursos naturais, força econômica, força militar, estabilidade política, entre outros. (NYE, 1990).

A questão sobre o poder é um problema básico que surge quando pensamos em poder em termos de recursos. Alguns países são melhores que outros em converter seus recursos em influência efetiva... A questão sobre o poder é a capacidade de converter um poder em potencial, medido por recursos, em poder efetivo, medido pela mudança de comportamento de outros. (NYE, 1990, p.178).

O mundo pós-guerra fria, marcado pelo desaparecimento dos conflitos ideológicos bipolares e pela emergência de temáticas secundárias, traz um novo significado para o conceito de segurança. A segurança deixa de ser apenas a luta militar pela manutenção da integridade territorial de cada Estado, passando a abranger problemáticas as quais envolvem o indivíduo e a sociedade mundial. (CHAGAS-BASTOS, 2010).

Nesse sentido, temáticas relacionadas ao meio ambiente foram incorporadas à agenda internacional e ganharam status de estratégicas, uma vez que o tema passou a não ser mais tratado como meramente ambiental, envolvendo também, entre outras, questões comerciais, tecnológicas, estratégicas, de direitos de propriedade intelectual, biotecnologia, desenvolvimento, energia, segurança física, patrimonial e alimentar. Proteger os recursos tornou-se uma das principais funções de segurança do Estado. (BARROS-PLATIAU, 2011).

Para a maioria dos países, portanto, a busca ou proteção de recursos naturais se tornou uma característica primordial no planejamento da segurança nacional e internacional, tendo em vista que a proliferação de conflitos acerca de recursos naturais como a água, petróleo e diamantes em época de escassez, assim como as consequências das mudanças climáticas, do desmatamento e da poluição, engloba riscos diretamente ligados à segurança individual das pessoas. (KLARE, 2002).

A perda da biodiversidade deixa de ser apenas uma questão ambiental, passando a englobar também temáticas econômicas, de desenvolvimento, segurança global, ética e moral. A perda contínua e crescente da biodiversidade prejudicará a realização da maioria dos ODS, incluindo a redução da pobreza e segurança alimentar, hídrica e energética. A biodiversidade tem valor econômico significativo; é uma questão de segurança, na medida em que a perda de recursos naturais pode levar ao conflito; é uma questão ética, porque a sua perda prejudica as pessoas mais pobres que dependem dela, evidenciando ainda mais a desigualdade do mundo; e é também uma questão de autopreservação. (ALMOND, GROOTEN E PETERSEN, 2020).

A vida humana e seus esforços dependem fundamentalmente de bens e serviços que são fornecidos e regulados pela biodiversidade, incluindo alimentos, água limpa, mitigação do clima e conexões culturais. A série de eventos catastróficos recentes têm mostrado que a conservação da biodiversidade é mais que um compromisso ético para com a humanidade: é um investimento estratégico e inegociável para preservar a saúde, riqueza e segurança do homem. Portanto, fica claro que as consequências sociais e econômicas da degradação ambiental são catastróficas e que a 
proteção da saúde, da riqueza e da segurança humana estão intrinsecamente relacionadas à proteção da saúde ambiental. (ALMOND, GROOTEN E PETERSEN, 2020).

Ao entender o meio ambiente como provedor, dentre outros, de dignidade, de energia limpa e renovável, de biotecnologia e de biodiversidade, os Estados ganham uma ferramenta de poder de considerável peso num cenário de reconfiguração das relações internacionais. A escassez dos recursos naturais necessários à reprodução da vida, relacionada ao direito ambiental internacional, ao desenvolvimento sustentável, à ameaça à sobrevivência dos atores e à segurança ambiental internacional, estruturam a nova interface do sistema internacional, no qual, além dos tradicionais fatores econômicos, políticos e militares, os fatores ambientais também são considerados recursos de poder. (CHAGAS-BASTOS, 2010).

O Brasil tem em seu território de 15 a 20\% da biodiversidade total do planeta. O país apresenta a maior diversidade de flora do mundo, com um número superior a 55 mil espécies descritas; os mais ricos ecossistemas em número de espécies vegetais (Amazônia, Mata Atlântica e Cerrado); a maior diversidade de plantas superiores, peixes de água doce e mamíferos, a segunda maior em anfíbios, a terceira em aves e a quinta em répteis. (PESSOA E SANTOS, 2014).

A Amazônia representa uma parcela significativa dessa megadiversidade brasileira. A bacia amazônica contém diversos ecossistemas; relevante riqueza em termos de diversidade biológica e étnica; a maior extensão de floresta tropical da Terra (mais de 5 milhões de $\mathrm{km}^{2}$ ); e um quarto das espécies animais e vegetais do planeta. A floresta tropical amazônica é tanto um absorvedor de carbono, e, portanto, uma reguladora da temperatura global e responsável pela redução das emissões de gases globais, quanto uma importante fonte de água doce. A descarga média do rio Amazonas no Oceano Atlântico corresponde a 18\% da descarga total de água fresca nos oceanos do mundo. (NOBRE, 2002).

Segundo Rubens Ricupero (2012), o Brasil é uma espécie de potência ambiental porque tem cinco trunfos: é detentor da maior floresta tropical do mundo, a Amazônia; a maior reserva de água doce disponível; uma das maiores reservas de biodiversidade; tem uma matriz energética de 40\% de energia limpa e renovável; e é o único país do mundo que tem um programa de combustível extraído da biomassa em escala de milhões de veículos, que é o etanol. O Brasil é uma potência ambiental se considerada sua abundância de recursos naturais: desempenha o mais importante processo de captura de carbono florestal do mundo; o maior estoque de biodiversidade; a maior reserva de terras agricultáveis; o agrobusiness mais competitivo; o terceiro maior estoque de água potável; a produção de etanol mais eficiente e a segunda em quantidade produzida; e a maior reserva de energia hidráulica. (VIOLA E FRANCHINI, 2012). O país é ainda o primeiro produtor mundial de várias commodities, o que garante a sua segurança alimentar; tem grande potencial tecnológico para prospecção de petróleo e produção de biocombustíveis, o que é positivo para sua segurança energética e econômica; e detém matriz de oferta energética limpa, o que deixa o Brasil numa posição 
muito confortável quanto à geração de energia em comparação com o restante do mundo. (BARROSPLATIAU, 2011).

Somado a isso, do ponto de vista legal, o Brasil é signatário de quase todos os acordos ambientais multilaterais e tem um arcabouço legal ambiental consolidado se comparado com qualquer país desenvolvido ou emergente. Ainda, é um dos poucos a ter um direito penal ambiental, instituído pela Lei $n^{0}$ 9.605, de 12 de fevereiro de 1998, a Lei de Crimes Ambientais, que serve de modelo para outros países interessados em seguir o mesmo caminho. Uma iniciativa importante foi o advento da Constituição de 1988, chamada de Constituição Verde, como parte da Ordem Social e, portanto, como direito social do homem. (BARROS-PLATIAU, 2011). No Capítulo VI do Título VII Art. 225 da Carta Constitucional Brasileira (1988), consta:

Todos têm direito ao meio ambiente ecologicamente equilibrado, bem de uso comum do povo e essencial à sadia qualidade de vida, impondo-se ao Poder Público e à coletividade o dever de defendê-lo e preservá-lo para as presentes e futuras gerações.

Esse trecho do texto constitucional estabelece o meio ambiente como um direito fundamental, no sentido de que a vida, para sua integralidade, depende também da proteção do meio ambiente, pois este é capaz de prover não somente as necessidades econômicas, mas também as humanas. A Constituição Federal Brasileira de 1988 inovou ao concretizar o direito à proteção ao meio ambiente como direito de todos, estabelecendo-o ainda como bem de uso comum da sociedade e essencial à qualidade de vida. (NIENCHESKI, 2014). A Carta, em seu art. 170, também estabelece princípios gerais da atividade econômica, destacando a defesa do meio ambiente através de um conjunto de direitos e obrigações a serem exercidos tanto pelos cidadãos como pelo Estado, buscando garantir a instrumentalização da proteção ambiental. (CALSSING, 2010).

O detalhamento dos excertos constitucionais que tratam da questão ambiental no Brasil tem como objetivo demonstrar a aderência de nossa Carta Maior ao novo entendimento que o meio ambiente passou a adquirir sem que, contudo, se pretendesse adentrar nas divergências jurisprudenciais emanadas pelas cortes superiores relacionadas com a temática.

O Brasil desempenha papel fundamental no contexto da atual crise ambiental global. Detentor de 60\% da floresta amazônica e de 12\% de toda água doce disponível no planeta, o país possui recursos naturais de grande relevância para o Sistema Internacional. A destruição ou degradação da sua biodiversidade impactaria muitos Estados, se não todos. Diferente de países como China, Estados Unidos, Índia, Rússia e Japão, os quais detém poder em forma de armas nucleares e consolidadas forças militares, o Brasil, como potência ambiental, também é detentor de poder, contudo talvez não o esteja utilizando da maneira mais apropriada. (WALT, 2019). 


\section{A BIODIVERSIDADE BRASILEIRA COMO INSTRUMENTO DE BARGANHA NO SISTEMA INTERNACIONAL}

O Brasil é alvo de constante atenção da comunidade internacional por conter grandes reservas de recursos naturais, por ser o maior repositório de biodiversidade do planeta e por ser o maior país tropical do mundo, com a maior quantidade de plantas e florestas intactas. Tendo em vista que o país é a principal economia da América Latina, uma liderança regional e uma potência ambiental, é esperado que o Brasil tenha um protagonismo ambiental a nível global. (VIOLA E FRANCHINI, 2012). Desde o primeiro momento, o país ocupou posições importantes nas discussões referentes ao meio ambiente, participando das quatro grandes conferências ambientais internacionais: Conferência de Estocolmo (1972), Conferência do Rio (1992), Rio+10 (2002) e Rio+20 (2012), nas quais procurou enfatizar questões cruciais para o seu desenvolvimento. (LAGO, 2013).

Na Conferência de Estocolmo, o Brasil atuou em defesa dos países emergentes, defendendo a liberdade deles de utilizarem os recursos naturais para extrair riqueza. Na Conferência do Rio, o país teve uma posição mais consciente, liderando discussões e encorajando países a aprovarem ações concretas de preservação e desenvolvimento sustentável. Na Rio+10, o Brasil foi porta-voz do Grupo dos 77 e China nas seções de proteção e gestão de base de recursos naturais, de globalização e de meios de implementação, bem como liderou a tentativa de fixação de uma meta para energias renováveis de matriz energética. (LAGO, 2006). Na Rio+20, a posição brasileira foi conservadora e pouco contribuiu para gerar algum consenso em torno da proteção dos recursos comuns da humanidade, reforçando o seu papel como potência ambiental subdesenvolvida. (VIOLA E FRANCHINI, 2012).

Vale destacar também o protagonismo do Brasil junto às negociações dos termos do Acordo de Paris e, quando firmado, pelas medidas audaciosas de mitigação, adaptação e meios de implementação. A ambição dessa contribuição fortaleceu a posição negociadora do Brasil em Paris e colocou o país na vanguarda dos esforços de combate à mudança do clima, de forma que o texto do Acordo incorporou propostas brasileiras, a exemplo do Mecanismo de Desenvolvimento Sustentável, artigo 6.4, e as principais linhas de diferenciação entre países desenvolvidos e em desenvolvimento, artigos 4.3, 4.4, 9.1 e 9.2. (PARECER NORMATIVO No 728 DE 11 DE AGOSTO DE 2016).

O Brasil, portanto, sempre esteve presente nas negociações ambientais multilaterais, seja como alvo de críticas internacionais acerca de sua política ambiental, seja como ator dinâmico. Em outros termos, o país conseguiu transformar seus recursos em instrumentos de barganha política. É possível identificar que em poucos anos o Brasil mudou sua postura nas conferências, passando de um país que se recusava a assumir metas obrigatórias de mitigação para um país que apresentava seus dados e relatórios, dando exemplos de conduta para outros países. Contudo, a estratégia diplomática de inserção do Brasil foi mudando ao longo dos últimos anos, quando as economias 
emergentes se tornaram também responsáveis pelas maiores taxas de emissão de gases do efeito estufa. Além disso, o país tomou decisões convergentes com a agenda ambiental nas décadas passadas ao optar por energia hidroelétrica e biocombustíveis. (BARROS-PLATIAU, 2011).

A governança ambiental no Brasil pode ser dividida em três grandes períodos: pré-2005, um período com governança muito pobre e altas taxas de desmatamento; os anos entre 2005 e 2012, quando houve melhorias na governança ambiental e resultados efetivos na redução do desmatamento, principalmente na Amazônia; e os anos entre 2012 e 2017, quando a governança sofreu uma erosão gradual com a anistia concedida aos desmatadores ilegais através da flexibilização do Código Florestal de 2012, aumentando os índices de desmatamento na Amazônia brasileira. Desde então, o governo brasileiro vem aprofundando essa reversão, tentando desconstruir várias políticas ambientais de sucesso. (ROCHEDO ET. AL, 2018).

A Amazônia brasileira desempenha papel central em vários problemas ambientais globais da atualidade, indicando a importância e compromisso do Brasil de preservar o meio ambiente e a economia humana que se encontram embutida nela (FEARNSIDE, 2002). Durante muito tempo, o Brasil liderou a redução do desmatamento na Amazônia, através do estabelecimento de instituições científicas independentes, garantindo um monitoramento rigoroso e transparente, de agências de controle competentes e do reconhecimento de territórios indígenas. (BBC NEWS, 2020).

No entanto, os números de desmatamento e queimadas na Amazônia brasileira têm atingido os níveis mais altos dos últimos anos, apresentando, anualmente, aumentos expressivos e sucessivos: 5,o mil km² em 2014, 6,2 mil km² em 2015 e 7,9 mil km² em 2016. Apesar de uma queda no ano de 2017, o desmatamento voltou a crescer em 2018, chegando a 7,9 mil km². (MINISTÉRIO DO MEIO AMBIENTE, 2019). O Instituto Nacional de Pesquisas Espaciais (INPE) verificou que, entre agosto de 2018 até julho de 2019, as taxas de desmatamento foram 40\% maiores do que no período anterior. (EXAME, 2019). No ano de 2019, mais de 76.00o incêndios florestais foram contabilizados no Brasil, somando 1,3 milhão de hectares perdidos, a maioria na Amazônia, totalizando um aumento de mais de 80\% em relação ao ano de 2018, colocando o Brasil como responsável pela destruição de um terço de todas as florestas tropicais virgens do planeta em 2019. (ANDRADE, 2019).

A floresta tropical amazônica é um absorvedor de carbono, uma reguladora da temperatura global e uma importante fonte de água doce. O desflorestamento já afetou sua capacidade de performance nesses três papéis e cientistas estimam que o aumento do calor e de condições secas podem transformar grande parte da floresta em uma savana. (WALT, 2019). A rápida proliferação de incêndios florestais e o aumento de desmatamentos se tornaram um problema diplomático com múltiplas repercussões internacionais. A demora na resposta por parte do governo brasileiro frente a essas questões trouxe como consequência, além das críticas da imprensa local e internacional, uma série de declarações de líderes internacionais repudiando a inércia do governo brasileiro para combater os incêndios e desmatamentos. 
No que se refere aos compromissos firmados, em agosto de 2015, o Brasil assinou A Declaração Conjunta Brasil-Alemanha sobre Mudança do Clima visando cessar o desmatamento ilegal na Amazônia brasileira até 2030, assim como compensar as emissões de gases de efeito estufa oriundas da extinção da vegetação. Em novembro do mesmo ano, o país assinou uma declaração de compromisso com a Noruega para reduzir o desmatamento e a degradação da floresta. (MINISTÉRIO DO MEIO AMBIENTE, 2020). Esses dois países realizaram significativos repasses para o Fundo Amazônia, criado em 2008 para arrecadar recursos financeiros para custear ações de prevenção, conservação, monitoramento e combate ao desmatamento. Do total de recursos recebidos, que já supera $\mathrm{R} \$ 3,4$ bilhões, a Noruega era a principal doadora (94\%), seguida da Alemanha (5\%) e da Petrobras (1\%). (EXAME, 2019).

Apesar dos compromissos firmados, o governo brasileiro não tomou iniciativas para reverter os crescentes indicadores de desmatamento. Contrariamente, em troca de apoio político, assinou atos provisórios e decretos afrouxando os requisitos de licenciamento ambiental, suspendendo a ratificação das terras indígenas, reduzindo as áreas de proteção e facilitando os grileiros a obterem escrituras de áreas desflorestadas ilegalmente. (ROCHEDO et. al, 2018). O consequente aumento no desmatamento, portanto, somado à alteração da estrutura do Fundo Amazônia e à falta de políticas ambientais respeitadas pelo governo brasileiro implicaram, em agosto de 2019, no congelamento de novos repasses da Noruega e Alemanha para o Fundo. (ARMADA, 2020).

O Fundo Amazônia é um exemplo do que Sippel e Neuhoff chamam de "condicionalidade climática”, um tipo de soft power que implica em ameaças de retenção de benefícios financeiros, diplomáticos e técnicos, entre outros, de um Estado para outro para obrigá-lo a adotar ações que minimizem as mudanças climáticas. Essas políticas podem incluir ações coercitivas, mas também podem ser de cooperação, oferecendo benefícios mútuos, considerando que as condicionalidades climáticas sejam cumpridas. (SIPPEL E NEUHOFF, 2009).

O aumento de queimadas e desmatamentos na Amazônia, somadas à inércia do Brasil frente a essas questões e a algumas decisões recentes do governo, geraram repercussões negativas no cenário internacional. Ações como: transferir órgãos de controle ambiental para outras pastas; reduzir a atuação do Ministério do Meio Ambiente; exonerar funcionários do Instituto Brasileiro do Meio Ambiente e dos Recursos Naturais Renováveis (IBAMA) e do Instituto Chico Mendes de Conservação da Biodiversidade (ICMBio); demitir o diretor-geral do INPE; culpar as ONGs pelo desmatamento e queimadas; e duvidar dos dados do INPE fomentam a falta de comprometimento brasileiro frente aos compromisso assumidos com as questões ambientais. (BARRUCHO, 2019).

A falta de credibilidade e confiança no governo brasileiro frente às questões ambientais gera consequências econômicas concretas, prejudicando o mercado exportador e quem depende do investimento externo. (BARRUCHO, 2019). Em abril de 2019, 609 cientistas solicitaram à União Europeia (UE) garantias do Brasil para a proteção dos Direitos Humanos e do Meio Ambiente, através do condicionamento das negociações comerciais. Ou seja, insistiram que essas negociações 
passassem a ser condicionadas pelo cumprimento dos compromissos de proteção ambiental, combate às mudanças climáticas e respeito aos direitos humanos. (SILLS, 2019).

Nesse sentido, o acordo UE-Mercosul, o qual vem sendo negociado há mais de 20 anos, tem encontrado dificuldades de implementação frente às preocupações acerca dos seus impactos ambientais, principalmente na Amazônia. Alguns países como a Áustria, Holanda e França já anunciaram que não assinariam o acordo por duvidarem do compromisso brasileiro com o meio ambiente, colocado em xeque pelo aumento do número de queimadas e áreas desmatadas, bem como pelo fato do acordo não prever mecanismos de sanção caso o Brasil não cumpra com as cláusulas para proteção da floresta tropical. (DW, 2020).

No lançamento da cúpula do G7, o grupo das maiores economias do mundo, em agosto de 2019, o presidente francês Emmanuel Macron afirmou que a Amazônia é um "bem comum" da humanidade, criticando as queimadas na região. Na mesma ocasião, o presidente francês anunciou que os países membros do $\mathrm{G} 7$ haviam aprovado um pacote de ajuda de $£ 18$ milhões para combater os incêndios na região. O governo brasileiro minimizou o impacto das queimadas e rejeitou a ajuda. (LE MONDE, 2019).

O mês de julho deste ano foi marcado pelo pedido de afastamento de Ricardo Salles do posto de Ministro do Meio Ambiente, através da Ação Civil Pública no 1.16.000.0oo912/2020-18, o pedido foi feito por procuradores do Ministério Público Federal (MPF), sob a justificativa de que o ministro vinha atuando com a intenção de desestruturar a política ambiental do Brasil, cometendo atos ilegais ou contrários aos princípios básicos da Administração Pública do país, como: desestruturação normativa, quando assina decisões que contribuem para enfraquecer a estrutura de leis ambientais; desestruturação dos órgãos de transparência e participação, como no episódio do esvaziamento de conselhos consultivos; desestruturação orçamentária; e desestruturação fiscalizatória, referente ao desmonte de órgãos de fiscalização ambiental. De fato, sob a gestão ambiental de Salles, o país teve um aumento da taxa de desmatamento e dos focos de queimadas, ao mesmo tempo em que apresentou o menor número de multas por crimes ambientais dos últimos 20 anos.

No mês de setembro, quando a destruição do Pantanal pelas queimadas chegou a quase 3 milhões de hectares, oito países europeus enviaram uma carta aberta ao vice-presidente brasileiro, Hamilton Mourão, protestando contra a política ambiental brasileira e reivindicando um comprometimento do governo em aplicar ações reais e imediatas para reduzir o desmatamento. A carta alegou que as preocupações com a situação ambiental no Brasil atingem consumidores, negócios, investidores e a sociedade civil na Europa. O desmatamento no país está tornando cada vez mais difícil para que empresas e investidores mantenham seus critérios de sustentabilidade. (BBC NEWS, 2020).

O debate entre os então candidatos à presidência dos EUA, Donald Trump e John Biden, ocorrido em 29 de setembro de 2020, também abordou as queimadas da Amazônia e Pantanal brasileiros. Na ocasião, Biden afirmou que, se eleito, conduziria articulações para que o Brasil 
parasse de destruir a Amazônia. Caso isso não acontecesse, ameaçou gerar consequências econômicas significativas. (CNN NEWS, 2020).

A falta de comprometimento brasileiro frente às responsabilidades assumidas com as questões ambientais tem acarretado no aumento de medidas coercitivas. Como exposto no segundo capítulo deste trabalho, nas questões internacionais, poder utilizável se distingue do não utilizável quando se tem a utilização de um recurso interno de um Estado como instrumento de política exterior ao seu favor. O acordo da Alemanha e Noruega para o Fundo Amazônia e o pacote de $£ 18$ milhões aprovado pelos países do G7 para combater os incêndios na região são exemplos de soft power, os quais se utilizam da natureza brasileira como recurso de poder em favor do Brasil, enquanto a carta dos 609 cientistas e o condicionamento da UE no acordo comercial com o MERCOSUL é um exemplo da biodiversidade nacional sendo utilizada como instrumento de barganha contra o país. A carta aberta ao vice-presidente, por sua vez, é um retrato da questão ambiental como uma questão estratégica e de segurança.

A partir do momento que o atual quadro ambiental brasileiro afeta diretamente direitos constitucionais, como o direito à vida, à habitação e ao meio ambiente, e tem a capacidade de interferir na dinâmica climática do planeta, tem-se uma questão de securitização ambiental, uma vez que os riscos gerados pelas queimadas e desmatamentos na Amazônia estão diretamente relacionados à segurança individual das pessoas. (PEREIRA, 2015). Dessa forma, o meio ambiente como recurso de poder sinaliza a securitização da questão ambiental global. O Brasil, sendo um país megadiverso, está inserido nesse novo contexto no qual a temática ambiental é determinante para as relações internacionais e, o que está acontecendo no país, talvez seja apenas o ponto de partida para futuros conflitos envolvendo reservas naturais em outras partes do planeta.

\section{CONSIDERAÇÕES FINAIS}

A presente pesquisa trouxe um panorama da crise ambiental global da atualidade, do aumento da conscientização acerca do meio ambiente e do entendimento mundial deste como um direito fundamental, buscando compreender como, a partir dessas premissas, o Brasil utiliza a sua biodiversidade e seus recursos naturais como instrumento de barganha no Sistema Internacional. Tendo em vista a importância dos recursos brasileiros nesse contexto, sendo detentor de 15 a 20\% de toda a biodiversidade do planeta, de $60 \%$ da floresta amazônica e de $12 \%$ de toda água doce disponível na Terra, fica evidente que o Brasil é detentor de poder no cenário internacional.

Contudo, como exposto neste artigo, a atuação do governo brasileiro frente ao combate das queimadas e desmatamentos, principalmente na Amazônia e Pantanal, tem despertado a atenção de lideranças internacionais, como chefes de Estado, ministros, cientistas e da imprensa em geral, os quais têm respondido por meio de ameaças de sanções econômicas, congelamento de investimentos 
e/ou interrompendo a evolução de acordos comerciais, por exemplo. Desta maneira, fica evidente que a biodiversidade brasileira é um recurso de poder utilizável que, no entanto, não vem sendo aproveitado pelo Brasil, mas, pelo contrário, vem sendo utilizado como instrumento de barganha contra o país.

Faz-se necessário reconhecer que este trabalho priorizou a reflexão acerca das queimadas e desmatamentos na Amazônia, não abarcando os problemas relativos aos outros recursos naturais e biomas brasileiros, isso porque os problemas ambientais relacionados à Amazônia Brasileira são os que estão em evidência na atualidade e que estão sendo destacados pelos atores internacionais. Contudo, é fato que outras problemáticas irão despontar, muito provavelmente relacionadas aos recursos hídricos. A água é essencial para a sobrevivência humana e não existe outro recurso que possa substituí-la.

Dada a importância vital da água às atividades humanas, guardar dentro de suas fronteiras volumes de água que podem sustentar a sua população por um longo prazo, é um fator estratégico, mais ainda se for possível abastecer outros Estados. Abundantes reservas hídricas podem proporcionar aos Estados novas fontes de poder, tendo a capacidade de barganhar em outros setores da agenda internacional, usando como instrumento de pressão. Nesse sentido, problemáticas relacionadas à escassez hídrica se tornam um potencial objeto de pesquisa, assim como o papel das reservas brasileiras nesse cenário.

A partir do crescimento do entendimento sobre a importância do meio ambiente para a manutenção do homem na Terra, tem-se um aumento nos debates acerca de sua preservação e da relação entre recursos naturais e recursos de poder. Assim, o meio ambiente e seus recursos passam a ser considerados novas fontes de poder para os Estados. Nesse sentido, o Brasil, como potência ambiental, está perdendo a oportunidade de usar a conservação da sua biodiversidade como instrumento de barganha no sistema internacional a seu favor, permitindo que ela seja utilizada como recurso de poder por outros Estados contra o país.

*Artigo recebido em 24 de janeiro de 2021, aprovado em 13 de julho de 2021.

\section{REFERÊNCIAS}

AÇÃO CIVIL PÚBLICA - MINISTÉRIO PÚBLICO FEDERAL - no 1.16.000.000912/2020-18.

ACORDO de Paris = PARIS Agreement. 12 dez. 2015. Disponível em: <https://unfccc.int/sites/default/files/resource/docs/2015/cop21/eng/logro1.pdf> $>$. Acesso em: 14 abr. 2021. 
ALMOND, R.E.A.; GROOTEN M. and PETERSEN, T. (Eds). Living Planet Report 2020: Bending The Curve of Biodiversity Loss. WWF, Gland, 2020. Disponível em: <https://livingplanet.panda.org/en-us/> . Acesso em: 04 out. 2020.

ANDRADE, Rodrigo de Oliveira. Alarming surge in Amazon fires prompts global outcry. Nature. 23 ago. 2019. Disponível em: <https://www.nature.com/articles/d41586-019-02537-0 >. Acesso em: 18 ago. 2020.

ARMADA, C. A. S. A Teoria do Decrescimento como alternativa para o Mito do Crescimento Econômico Contínuo. Caderno Científico CECIESA - Gestão. Itajaí, v.3, n. 1, p. 263 - 271, 2017. Disponível em: <https://siaiap32.univali.br/seer/index.php/cccg/article/view/11474/6550> Acesso em: 8 mai. 2020.

ARMADA, C. A. S. Climate Change Law and Brazil: Climate Litigation as the Ultimate Ratio? SSRN, [s.l], 2020. Disponível em: <https://papers.ssrn.com/sol3/papers.cfm?abstract id=3640847>. Acesso em: 02 set. 2020.

ARMADA, C. A. S. Governança Global e Justiça Ambiental Face aos Desafios da Mudança Climática Planetária. 2016. Tese (Doutorado em Ciência Jurídica) - Universidade do Vale do Itajaí, Itajaí, 2016.

BARROS-PLATIAU, A. F. O Brasil na governança das grandes questões ambientais contemporâneas. IPEA, Brasília, $n^{0}$ 1618, 2011. Disponível em: <https://www.econstor.eu/handle/10419/91189>. Acesso em: 07 set. 2020.

BARRUCHO, L. Ação de Bolsonaro alimenta tese de que Amazônia é 'bem comum', dizem brasilianistas. BBC News, ago. 2019. Disponível em: <https://www.bbc.com/portuguese/brasil49462703 >. Acesso em: 03 ago. 2020.

BOSSELMANN, Klaus. Direitos Humanos, Meio Ambiente e Sustentabilidade. In: SARLET, Ingo Wolfang (Org.). Estado Socioambiental e Direitos Fundamentais. Porto Alegre: Livraria do Advogado Editora, 2010, p.91.

BRASIL. Comissão de Relações Exteriores e Defesa Nacional. Do parecer sobre o Projeto de Decreto Legislativo $n^{0}$ 19, de 2016 (PDC $n^{0} 428$, de 2016, na origem), que aprova o texto do Acordo de Paris sob a Convenção-Quadro das Nações Unidas sobre Mudança do Clima - UNFCCC, celebrando e Paris, em 12 de dezembro de 2015, e assinado em Nova York, em 22 de abril de 2016. Parecer normativo no 728 de 11 de agosto de 2016. Relatora: Kátia Abreu. Disponível em:

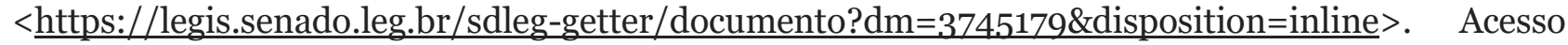
em: 19 out. 2020.

BRASIL. Constituição (1988). Constituição da República Federativa do Brasil de 1988. Brasília, DF: Presidência da República, 2020 Disponível em: <http://www.planalto.gov.br/ccivil 03/Constituicao/Constituicao.htm>. Acesso em: 31 out. 2020.

BRASIL. Ministério do Meio Ambiente. Declaração Conjunta Brasil-Alemanha sobre Mudança do Clima. Disponível em: $<$ https://www.mma.gov.br/images/arquivos/clima/convencao/indc/Declaracao Conjunta Brasil -Alemanha.pdf >. Acesso em: 01 set. 2020.

BRASIL. Ministério do Meio Ambiente. Desmatamento na Amazônia Legal. 2019. Disponível em: <https://www.mma.gov.br/mma-em-numeros/desmatamento>. Acesso em: 18 ago. 2020.

BRASIL. Ministério do Meio Ambiente. Joint Press Statement of the Governments of Brazil on Norway, Paris, November 3oth, 2015. Disponível em: 
<https://www.mma.gov.br/images/arquivos/clima/convencao/inde/Declaracao Conjunta Brasil -Noruega.pdf >. Acesso em: 25 ago. 2019).

BRASIL. Proposta de Emenda à Constituição no 13, de 26 de fevereiro de 2015. Institui o Código Civil. Diário Oficial da União: seção 1, Brasília, DF, ano 139, n. 8, p. 1-74, 11 fev. 2015.

CALSSING, R. A. O Direito Humano Fundamental ao Meio Ambiente Sadio: Convergência das Proteção Ambiental nos Âmbitos Nacional e Internacional. Revista do Curso de Mestrado em Direito da UFC, p. 161-167, 2010.

CHAGAS-BASTOS, F. H. Geografia política da água e seus recursos de poder no início do século XXI. Meridiano 47, Brasília, v. 11, n. 122, p. 18-26, 2010. Disponível em: < https://periodicos.unb.br/index.php/MED/article/view/4230/3874>. Acesso em: 20 jul. 2020.

COLOMBO, S. Da Noção de Soberania dos Estados à Noção de Ingerência Ecológica. Direitos Fundamentais e Democracia, 2007. Disponível em: $<$ https://revistaeletronicardfd.unibrasil.com.br/index.php/rdfd/article/view/75>. Acesso em: 12 set. 2020.

COMPARATIVE CONSTITUTION PROJECT. Constitute. Disponível em: <https://www.constituteproject.org/search?lang=en\&key=env\&status=in force $>$. Acesso em: 20 set. 2020.

EXAME. Inpe indica alta de 40\% em desmatamento, mas governo contesta. 2 ago. 2019. Disponível em: <https://exame.abril.com.br/brasil/inpe-indica-alta-de-40-em-desmatamentomas-governo-contesta/>. Acesso em: 18 ago. 2020.

EXAME. O que é o Fundo Amazônia e por que ele virou alvo do governo Bolsonaro. 10 ago. 2019. Disponível em: <https://exame.abril.com.br/brasil/o-que-e-o-fundo-amazonia-e-porque-ele-virou-alvo-do-governo-bolsonaro/>. Acesso em: o1 set. 2020.

FEARnSIDE, P. M. A Globalização do Meio Ambiente: O Papel da Amazônia Brasileira. Manaus: INPA, 2002.

KLARE, M. T. Resource Wars: the new landscape of global conflict. New York: Henry Holt and Company, 2002. E-book.

LAGO, A. A. C. do. Conferências de desenvolvimento sustentável. Brasília: FUNAG, 2013.

LAGO, A. A. C. do. Estocolmo, Rio, Joanesburgo: O Brasil e as Três Conferências Ambientais das Nações Unidas. Brasília: FUNAG, 2006.

L'AMAZONIE, bien commun universel. Le Monde, out. 2019. Disponível em: <https://www.lemonde.fr/idees/article/2019/08/24/l-amazonie-bien-commun-

universel 5502406 3232.html >. Acesso em: 10 ago. 2020.

MORgenthaU, H. J. A política entre as nações: a luta pelo poder e pela paz. Brasília: Universidade de Brasília, 2003.

NIENCHESKI, L. Z. Aspectos Contemporâneos do Direito Humano ao Meio Ambiente: Reconhecimento e Efetivação. ANIMA: Revista Eletrônica do Curso de Direito das Faculdade OPET, Curitiba, p. 60-83, 2014.

NOBRE, C. A. Amazônia e o carbono atmosférico: Estudos detalhados devem indicar mais claramente o papel da Amazônia no clima global. Scientific American Brasil, São Paulo, n. 6, v. 1, p. 36-39, 2002. Disponível em: 
<https://acervo.socioambiental.org/acervo/documentos/amazonia-e-o-carbono-atmosfericoestudos-detalhados-devem-indicar-mais-claramente>. Acesso em: 25 mai. 2020.

NYE, J. S. The Changing Nature of World Power. Political Science Quarterly, v. 105, n. 2, p. 177192, 1990. Disponível em: <www.jstor.org/stable/2151022>. Acesso em: 3 ago. 2020.

NYE, J. S. Think Again: Soft Power. Foreign Policy, Washington D.C., 23 fev. 2016. Disponível em: <https://foreignpolicy.com/2006/02/23/think-again-soft-power/>. Acesso em: 26 ago. 2020.

PARLAMENTO da Holanda Rejeita Acordo UE-MERCOSUL. DW, 04 jun. 2020. Disponível em: <https://www.dw.com/pt-br/parlamento-da-holanda-rejeita-acordo-ue-mercosul/a-53689521>. Acesso em: 12 ago. 2020.

PEREIRA, J. C. Environmental issues and International relations, a new global (dis)order - the role of International Relations in promoting a concerted international system. Revista Brasileira de Política Internacional, Brasília, v. 58, n.1, p. 191-209, 2015. Disponível em: $<$ https://www.scielo.br/scielo.php?pid=So034-73292015000100191\&script=sci abstract $>$. Acesso em: 15 jul. 2020.

PESSOA, L. G. A. M. C; SANTOS, M. R. de M. C. O Valor Econômico da Biodiversidade e os Países Megadiversos. In: SILVA, G. F.; RUSO, S. L. (Org.). Capacite: os caminhos para a inovação tecnológica. São Cristóvão: UFS, 2014, cap.3, p. 41-58.

QUEIMADAS no Pantanal e na Amazônia: carta aberta de países europeus a Mourão protesta contra política ambiental brasileira. BBC News, 16 set. 2020. Disponível em: <https://www.bbc.com/portuguese/brasil-54181888>. Acesso em: 23 set. 2020.

RICUPERO, Rubens. Brasil, potência ambiental. Conjuntura Econômica, o8 mai. 2012. Disponível em: <https://bibliotecadigital.fgv.br/ojs/index.php/rce/article/view/21940>. Acesso em: 05 mai. 2021.

ROCHEDO, P. R. R; SOARES-FILHO B., BRITALDO, S.; SCHAEFFER, R.; VIOLA, E.; SZKLO, A.; LUCENA, A. F. P.; KOBERLE, A.; DAVIS, J. L.; RAJÃO, R.; RATHMANN, R. The threat of political bargaining to climate mitigation in Brazil. Nature Climate Change, [s.l], n. 8, p. 695-699, 2018. Disponível em: <https://www.nature.com/articles/s41558-018-0213-y>. Acesso em: 7 jun. 2020.

SILLS, J. Make EU trade with Brazil sustainable. Science, v. 364, n. 6438, 26 abr. 2019. Disponível em: <https://www.science.org/doi/abs/10.1126/science.aaw8276 > . Acesso em: 12 ago. 2020.

SIPPEL, M.; NEUHOFF, K. A History of Conditionality: Lessons for International Cooperation on Climate Policy. Climate Policy, v. 9, $\mathrm{n}^{0}$ 5, p. 481-494, 2009, p. 485. Disponível em: <https://www.tandfonline.com/doi/abs/10.3763/cpol.2009.0634>. Acesso em: 10 set. 2020.

STEFFEN, W., RICHARDSON, K., ROCKSTRÖM, J., CORNELL, S., FETZER, I., BENNET, E., BIGGS, R., CARPENTER, S. \& VRIES, W. Planetary boundaries: Guiding human development on a changing planet. Science, [s.l.], v. 347, issue 6223, p. 735-746, fev. 2015. Disponível em: <https://www.science.org/doi/10.1126/science.1259855>. Acesso em: 24 abr. 2020.

TRUMP x Biden: Assista na íntegra o primeiro debate da eleição americana. CNN News, 29 set. 2020. Disponível em: <https://youtu.be/wYjjxjsNQvU>. Acesso em: o8 out. 2020.

VIEIRA, L. Antropoceno: As Ameaças à Humanidade. O Eco, [s.l.], fev. 2015. Disponível em: $<$ https://www.oeco.org.br/colunas/colunistas-convidados/antropoceno-as-ameacas-ahumanidade/>. Acesso em: 15 abr. 2020. 
VIOLA, E.; FRANCHINI, M. Sistema Internacional de Hegemonia Conservadora: O Fracasso da Rio+2O na Governança dos Limites Planetários. Ambiente e Sociedade, v. 15, n. 3, p. 1-18, 2012.

WALT, S. M. Who Will Save the Amazon (and How)? Foreign Police, ago. 2019. Disponível em: <https://foreignpolicy.com/2019/08/05/who-will-invade-brazil-to-save-the-amazon/>. Acesso em: 31 mar. 2020.

WWF. O último dia do ano nunca chegou tão cedo. Ago. 2016. Disponível em: <http://www.wwf.org.br/?53422>. Acesso em: 28 abr. 2020. 